\title{
Integrating research and advanced microscopy into the high school curriculum
}

\section{Craig Queenan, Alyssa Calabro, David Becker}

Craig Queenan, Alyssa Calabro, David Becker, "Integrating research and advanced microscopy into the high school curriculum," Proc. SPIE 8378, Scanning Microscopies 2012: Advanced Microscopy Technologies for Defense, Homeland Security, Forensic, Life, Environmental, and Industrial Sciences, 837811 (14 May 2012); doi: 10.1117/12.923443

Event: SPIE Defense, Security, and Sensing, 2012, Baltimore, Maryland, United States 


\title{
Integrating research and advanced microscopy into the high school curriculum
}

\author{
Craig Queenan*, Alyssa Calabro, David Becker \\ Bergen County Academies, Nano-Structural Imaging Lab, 200 Hackensack Avenue, Hackensack, \\ NJ 07601
}

\begin{abstract}
The Bergen County Academies (BCA) is a public magnet high school in New Jersey focused on science, technology, engineering and mathematics (STEM) education. The research program offered at the school offers students the opportunity to conduct, present and defend their own scientific research using advanced tools and techniques, including scientific equipment unavailable in most high schools, such as scanning and transmission electron microscopes. Through their journey into research, students are given a skill set that can be transferred to future education and their careers, and will help shape the next generation of leaders in the fields of science, technology, engineering and math. By serving as an educational model for reformed STEM education, BCA is at the forefront of what STEM education in the United States will look like in the years ahead.
\end{abstract}

Keywords: STEM, education, microscopy, SEM, TEM, science, curriculum

\section{INTRODUCTION}

Sir Ken Robinson, one of the premier leaders in educational development and reform, stated in a 2009 speech, "Every country on earth at the moment is reforming public education... People are trying to work out, 'How do we educate our children to take their place in the economies of the 21 st century'." 1 This statement succinctly captures the essence of the STEM education movement both in the United States and in other countries around the globe in recent years.

A logical sequence has been delineated which links the U.S. economy to the products, intellectual property, and commodities produced by STEM jobs; the overall health of the STEM workforce; and finally to the educational systems which recruit and cultivate STEM talent. Every stage of this chain is analyzed and evaluated as priorities for future U.S. competitiveness, innovation and security. The U.S. government, from the office of the President, to the National Science Board and the National Science Foundation, to the Commerce Department, has targeted advancement in STEM education as the "key element" for promoting economic growth and increasing the innovative capacity of our nation. ${ }^{2}$

Under this scrutiny, the underlying curricula for science education in the U.S. has been branded, "a mile wide and an inch deep," and as neglecting "the need for students to develop an understanding of the practices of science and engineering" ". To address these concerns, the National Research Council (NRC), an arm of the National Academies, has crafted a "Framework for K-12 Science Education," identifying practices, crosscutting concepts and core ideas which together, are being used to develop coherence in the "next generation of science standards." 3 They are doing so with the "aspiration that many states will choose to adopt them," as most have with the Common Core Standards for Math and Literacy $^{3}$. The NRC's framework goes a long way toward connecting K-12 science education to the skills, tools and efforts of the practicing scientist.

The National Science Board, part of the National Science Foundation, has focused its attention in STEM education on the, "identification and development of future STEM innovators." " In New Jersey, the Bergen County Academies (BCA) has developed a program in which independent research and advanced technologies have been paired with traditional STEM education to begin developing the students into the next generation of STEM innovators. The programs offered have become a model for cultivating STEM leadership and innovative potential at the high school level, and are unique in their perspective on science education, student take away, and the diversity of skills acquired by students.

*craque@bergen.org Office - 1(201)343-6000 x 4645 Lab - 1(201)343-6000 x 3336 Website: bcts.bergen.org/nsil 


\section{NATIONAL SCIENCE EDUCATION INITIATIVES}

\subsection{Fostering STEM leadership}

In May 2010, The National Science Board addressed the pipeline of talent transitioning from education institutions to the workforce in their report "Preparing the Next Generation of STEM Innovators", In the report, they specifically established the need for developing STEM innovators, and for incubating programs to serve this population. In the words of the Steven C. Beering, NSF Chairman, "The long-term prosperity of our Nation will increasingly rely on talented and motivated individuals who will comprise the vanguard of scientific and technological innovation." ${ }^{5}$ The NSB study addresses the "educational needs of our Nation's most talented and motivated students, who have the potential to become high-achieving members of the U.S. STEM workforce, or STEM innovators. (STEM 'innovators' are defined as those individuals who have developed the expertise to become leading STEM professionals and perhaps the creators of significant breakthroughs or advances in scientific and technological understanding). ${ }^{\prime 4}$ The report cites evidence from a 2002 Commission on Professionals in Science and Technology report that, "there is evidence that top U.S. students, who have a disproportionate potential to become future innovators, are eschewing careers in S\&E...Between 1992 and 2000, the number of the highest-achieving students intending to enter graduate study in a S\&E field declined 8 percent overall, with particularly steep declines in engineering ( 25 percent) and mathematics (19 percent)." They go on to cite a 2009 study which "provided evidence that, between the 1990s and mid-2000s, there was a sharp decline in the number of highest-achieving U.S. high school graduates enrolling in or completing a STEM major in college." The Board found "that talented students have some learning needs that are distinct from those of the general population" and called for an elevation of the ceiling of achievement for future innovators through the expansion of inquiry-based learning, peer collaboration, open-ended real-world problem solving, hands-on training, and interactions with practicing scientists, engineers and other experts. ${ }^{4}$

In 2009, the Obama administration launched the "Educate to Innovate" campaign to spur a nationwide effort to move American students to the top of the pack in science and math achievement over the next decade. The program seeks to "apply new and creative methods of generating and maintaining student interest and enthusiasm in science and math, reinvigorating the pipeline of ingenuity and innovation essential to America's success that has long been at the core of American economic leadership." ${ }^{\circ}$ For these reform initiatives to be successful, a national standard for science education must be established, with criteria in place to challenge students and improve the way science is taught in the United States.

\subsection{A national framework}

The National Research Council's initiative to provide a framework for science education provides practices, crosscutting concepts and core ideas linked to grade level attainment. ${ }^{3}$ This document aims to serve as a scaffold for later curriculum development initiatives. Their framework provides eight practices which they distinguish from skills in that the practices, "stress that engaging in scientific inquiry requires coordination both of knowledge and skill simultaneously.", They further consider these eight practices to be essential elements of the K-12 science and engineering curriculum (Figure 1).

PRACTICES FOR K-12 SCIENCE CLASSROOMS

1. Asking questions (for science) and defining problems (for engineering)

2. Developing and using models

3. Planning and carrying out investigations

4. Analyzing and interpreting data

5. Using mathematics and computational thinking

6. Constructing explanations (for science) and designing solutions (for engineering)

7. Engaging in argument from evidence

8. Obtaining, evaluating, and communicating information

Figure 1: The National Research Council's 8 Practices for K-12 Science Classrooms. ${ }^{3}$ 
The Bergen County Academies' programs sit firmly at the crux of the recommendations and initiatives of the NSB, the NRC and the White House. BCA's programs provide a model and methodologies for the development of STEM talent and innovative potential. The BCA model is grounded in the perspective that student development in STEM is best achieved through practical experience of journeying to the frontiers of science. The program considers the reality of how students apply, capitalize on, and find community in the scientific explorations and investigations they have conducted.

\section{THE BERGEN COUNTY ACADEMIES}

\subsection{Background}

The 2011-2012 school year marks the twentieth anniversary of the opening of the Bergen County Academies (BCA). BCA serves the residents of Bergen County, New Jersey, which consists of seventy-two towns with a total population of nearly one million residents. Unlike traditional public high schools, BCA is a magnet school that draws from the best prepared and most academically invested rising ninth graders from throughout the county. Importantly, being a public magnet school, students attend BCA tuition-free, meaning it is free of the economic barriers often cited as an impediment to STEM advancement.

The student body is made up of approximately 1,100 students who are enrolled into one of seven career focused academies upon matriculation: the Academy for the Advancement of Science and Technology (AAST); the Academy for Engineering and Design Technology (AEDT); the Academy for Medical Science Technology (AMST); the Academy for Telecommunications and Computer Science (ATCS); the Academy for Business and Finance (ABF); the Academy for Culinary Arts and Hotel Administration (ACAHA); and the Academy for Visual and Performing Arts (AVPA). Students at the school are highly motivated and display an interest in pursuing careers in the subject area of their academy. While all students must satisfy the state course requirements for graduation (which include successful completion of specific courses in English, mathematics, science, language and humanities), the course requirements for students in AAST and AEDT provide a greater focus on education in the STEM disciplines (Table 1).

In addition to students having a more focused curriculum than that which is found in most high schools, students also have an extended school day schedule, having classes scheduled from 8:00AM - 4:10PM. The extended day, along with the class scheduling system, affords students the opportunity to not only take a greater number of classes (most students carry 12-15 classes per trimester), but also to take more specialized classes and electives in their area of interest.

Offering a greater diversity of classes allows students the opportunity to broaden their knowledge base in specific content areas. However, it does nothing to address the call for reform in STEM education previously addressed. In order to improve upon the way that STEM disciplines are taught, students must be able to apply the information they learned in the classroom to problem-based, "real-world" scenarios, and discover how the scenarios have an impact beyond the walls of the school. The truly unique way that BCA approaches this is through its research programs and the integration of advanced microscopy into research and curriculum. 
Table 1. Core curriculum scope and sequence for students in AAST or AMST. (A) Requirements of both Academies;

(B) Requirements of AAST; (C) Requirements of AEDT. Elective classes are in addition to classes listed.

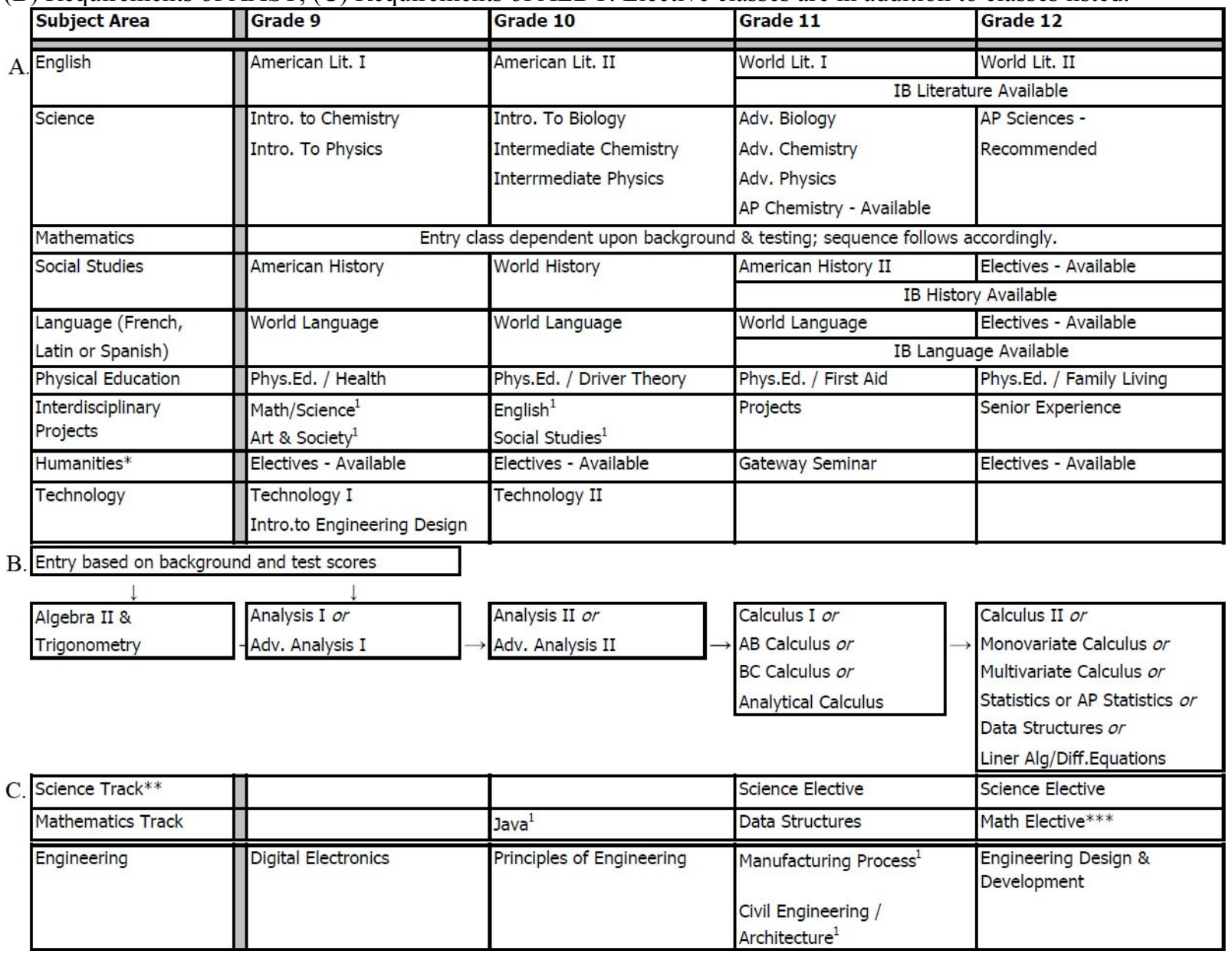

\subsection{The research program at $\mathrm{BCA}$}

The research program at BCA can be thought of as supplemental to the STEM education students receive rather than an alternative to traditional teaching methods; Research classes do not act as a standalone method of introducing students to STEM material. Alternatively, they reinforce subjects taught in traditional classroom environments, allow students to build upon principles, reexamine or approach material from a different vantage point, and apply their knowledge to an environment where the choices they make can be evaluated qualitatively and quantitatively in real-time.

Research at the school is presented as a journey for students to the "frontiers of science"- to the boundary between the known and the unknown. Students are introduced to research as the vehicle for understanding and advancing that boundary, and for sharing those advancements. Students learn how various tools, techniques, efforts, accomplishments and failures have been used to advance and connect scientific understanding. The student's journey begins with an investigation of the current boundary in an area of their choosing via the scientific literature. In conjunction with faculty and staff, the students design a project for their study. They then begin to gather a working understanding of the tools, techniques and skills they will need to master through hands-on training and practice. The students' research is conducted, data is collected and analyzed and their results presented to an audience, either in the form of a juried science competition or fair, poster presentation or publication. The research project is a foray into the world of the practicing scientist, where students are enticed by the excitement, potential, mystery and challenges which await them at the frontiers of science. 
The school has three distinct research programs: cell biology, genetics and molecular biology, and chemistry/ nanotechnology. A student who decides to take on research as part of their course of study is faced with a task that most college and even some graduate research students would struggle with: specify what topic in science most interests them and design a novel project around that idea. While it would be much easier to develop a series of "cookie cutter" experiments for research students, the faculty and mentors put few restrictions on the students, teaching them instead how to perform literature searches, how to draw pertinent information from publications, and how to use that information to design an experiment. For any student wanting to pursue a career in a STEM field, being able to analyze the primary literature in the field not only teaches them the background science, math, etc., but also teaches them how to use a very valuable tool that will undoubtedly assist them in high school, college and their careers. Although a large number of participants in research at BCA are enrolled in the STEM academies (AAST, AMST and AEDT), participation is not limited to these students, but instead is open to any student at the school.

Another important aspect of the research program has been providing students with equipment, instrumentation and technology that is cutting edge and currently relevant in their fields. Most other high school research programs require partnerships with local universities or institutions to carry out all of the work for a project off-site. Students at BCA are able to conduct most, if not all, experiments using the labs and equipment available at the school. Examples of some of the equipment available to students are shown in Table 2. Students are trained in safety, good lab practices (GLP), and how to successfully operate and gather data from an instrument if it is needed for their research. In order to challenge the students to develop leadership skills rather than become "button pushers", the emphasis is not placed on the operation of the equipment but instead on acquiring reliable data, how the data supports the research, data analysis and larger "realworld" implications. This provides reinforcement of the basic principles of STEM while at the same time using skills and tools that those students can utilize in the future in college, graduate school and in their careers.

Table 2. Examples of equipment and instruments available to students involved in STEM research or projects.

\begin{tabular}{|l|l|}
\hline Engineering Program & $\begin{array}{l}\text { 3D scanners for reverse engineering; CAD design software; 3D printers for rapid } \\
\text { prototyping; Computer Numerical Control (CNC) mills, lathes and abrasive water } \\
\text { jet; Coordinate Measurement Machine (CMM) for inspection of prototyped parts. }\end{array}$ \\
\hline $\begin{array}{l}\text { Cell and Molecular Biology } \\
\text { Research Programs }\end{array}$ & $\begin{array}{l}\text { Biosafety cabinets and incubators for cell culture; Fluorescence microscopes; } \\
\text { Microplate readers; Ultracentrifuge; Lypholizer; Electroporator; Flow cytometer; } \\
\text { Real-time (RT) PCR; Capillary electrophoresis DNA sequencer and analyzer. }\end{array}$ \\
\hline $\begin{array}{l}\text { Chemistry/Nanotechnology } \\
\text { Research Program }\end{array}$ & $\begin{array}{l}\text { High-performance liquid chromatography (HPLC); Gas chromatography-mass } \\
\text { spectrometry (GC-MS); Atomic absorption spectrophotometer; FTIR, UV and } \\
\text { visible spectrophotometers; Differential scanning calorimeter (DSC); Plasma } \\
\text { etcher; Probe station. }\end{array}$ \\
\hline
\end{tabular}

The most unique set of instrumentation available to the students at BCA is the suite of microscopes that are part of the school's Nano-structural Imaging Lab (NSIL). The NSIL primarily serves as the school's core imaging facility, where students have access to a dual-beam scanning electron microscope (SEM) with elemental analysis capabilities, a transmission electron microscope (TEM), and a laser-scanning confocal microscope (LSCM). As with the instruments listed in Table 2, students interested in using the microscopes are trained in safety, GLP, and proper operation, with the emphasis placed on the data acquired and larger implications. In addition to their utility in research, the microscopes have served as a novel tool to teach STEM principles and generate interest in STEM disciplines for students at the school.

\subsection{Integrating microscopy into research}

One of the primary ways that the electron microscopes at BCA are used is to provide supplementary data for the independent research projects described above. Students use the microscopes to image and characterize their samples, adding an increased layer of analysis to their work. The instruments are critical components of many student projects and improve students' overall grasp of nanoscale phenomena, as is the case with nanoparticle and nanomaterial synthesis projects coming out of the school's nanotechnology lab. Imaging samples using the SEM and TEM allow students to inspect and measure the shape, size, and concentration of their samples, while features such as energy-dispersive X-ray spectroscopy (EDS) allow students to verify relative composition and purity/contamination of samples. Other features, 
such as the SEM's focused ion beam (FIB), allow students to precisely mill nanoscale patterns and designs, which has utility in nano-engineering projects and material sample preparation.

The experience that the research faculty at BCA has brought with them from their time spent in academic, clinical, and industrial settings gives students a wealth of in-house knowledge regarding many research topics. However, the NSIL has also provided research students additional opportunities to learn the skills directly from practicing scientists. Faculty and staff at BCA have developed partnerships with researchers at local hospitals, corporations, universities and government research labs (see website for partners). By working on collaborative projects, a student has the opportunity to work in the NSIL to carry out portions of a research initiative developed by one of these groups. In doing so, the students learn to collect relevant data for their partners, analyze the data and present their findings to the researchers. Through this, students learn about the larger impact of the project and how it is being used for future applications in areas such as renewable energy, disease treatment, and improvement of manufacturing quality. The process of working through the steps of the scientific method, paired with the interactions with research partners, reinforces STEM principles while emphasizing skills such as analytical and presentation skills, which will be used by the students throughout their education and future careers. By challenging students to participate in the activities of practicing scientists, and actively engaging students with state-of-the-art facilities, interactions, and projects, it is believed that the opportunities available through the research program, and specifically in the NSIL, enhance the STEM education that students are receiving at BCA.

\subsection{Integrating microscopy into curriculum}

In addition to its role in the research program, microscopy has also been used to enhance the course curriculum at BCA. First, microscopy has been integrated into the curriculum through the creation of an Introduction to Microscopy elective at the school. Four important principles are addressed in this curriculum. The first is presentation of the background and theory of light and electron microscopy in a way that addresses the scientific discoveries and principles that went into the creation of the instruments and their operation. In doing so, topics in multiple areas of science, including biology, chemistry and physics, as well as engineering are taught. Secondly, the information provided in lecture is complimented with hands-on activities and exercises that teach students how to operate each instrument and the various ways samples need to be prepared for each instrument and type of analysis. Third, students analyze and generate summaries of not only their own data and images, but also to works of others, and present their work in written form. This analysis allows students to learn how to properly read and extract information from literature, and learn how to write scientifically, as distinct from writing for the humanities. Finally, the students must relate what they learned about microscopy to current topics and applications in science, and how current research and technology is shaping the future. The successful implementation of these pillars of the course curriculum provides students with a strong basis in STEM principles in addition to preparing them to incorporate microscopy into their research projects at BCA.

Additionally, microscopy is integrated into curriculum of other science courses to enhance classroom experiences. Students in a biology class that are learning about cell structure could simply use images and diagrams found in a textbook to show important components of cells. In contrast, having the NSIL at the school provides teachers the opportunity to have a class sit in front of the TEM to examine and identify cellular structures in real-time for themselves. The experience is memorable for the students, who get excited to use the technology, provides greater understanding and retention of the material. The experience is also often a first exposure to microscopy and acts as an introduction to research.

The third way microscopy has been integrated into the curriculum is through Spark Events. These exercises are aimed at students in non-STEM disciplines and are meant to introduce them to microscopy in a meaningful way. By doing so, students who might otherwise not consider themselves "science-minded" can have their interest in the field sparked through exciting hands on events. An example Spark exercise had students in a visual arts and graphic design class use the SEM to image samples that they had collected and brought in to the lab. In their time in the lab, each student had an opportunity to operate the SEM and learned background information on how it worked. The students then took the images they collected and learned about colorization using computer software, and created pieces of art from their micrographs. Rather than just giving a lab tour, the Spark Event paired the science behind the SEM with the student's interest in graphic design, and made for meaningful exercise to introduce a greater number of students to microscopy and STEM. 


\section{STUDENT BENEFITS AND FUTURE DIRECTION}

\subsection{Skills attained through research enhanced STEM education}

Earlier, the NRC's eight essential practices for successful science and engineering curriculum were discussed. As evidenced in the previous section, the educational opportunities available to students at BCA through research and the school's microscopy facility align closely with this framework. Since the framework is still in its early stages and has not yet been adopted on a state or national level, the faculty and staff of the research program at BCA have looked to six skills that students performing research attain while in the program. These "pillars" of research at BCA are important in conveying the program, how it enhances the students education at BCA and how it provides a transferable skill set that can be carried by a student into college, graduate school, and their careers.

Context and Perspective - A students understanding of the historical, societal and scientific context and impact of their research is important in developing the "why" of their research project. This question of "why is the project relevant or important' assists in justifying why a project should be carried out and supported. Learning how to perform literature searches, read journal articles and extract important details from past projects are important skills that a student takes away from research.

Tools and Techniques - BCA administration has been proactive in acquiring a diverse array of tools and instruments that allow students to study a wide range of topics with limited technological restrictions. Paired with the knowledge and expertise of the faculty, students in research learn not only how to operate instrumentation, but also learn how to design an experiment with the available tools, follow protocols and limit variables in a project, determine the best method to gather the data to support a question, and collect the data in a useful way using safe operation and GLP.

Collaboration - Research and science are not solitary efforts. Students in the research program learn that in order to succeed and work through complications that arise, collaboration with their peers, mentors and experts in the field is necessary. In learning how to communicate their issues, divide effort and reach out to individuals with more experience in a field, students learn that the science community is just that, a community and support system interested in advancing the furthest bounds of knowledge together.

Analysis and Justification - After developing the context for a project, learning the techniques and using the tools needed to collect data, working collaboratively with others, analyzing and justifying data are critical skills that students must learn. A student's ability to assess an image or find an answer in a maze of numbers is necessary and must be developed by trial and error. By learning how to analyze their data and understand the difference between results and significant results, students can begin to answer the questions in research that had no answers.

Quality and Failure - Over the course of their research, students begin to understand that the quality of their work and results is as important as the findings that it leads to. Through the research process, students learn to take pride in the work that was done and time that was put in, and understand that in research they will encounter failure. Understanding that failure in a project may in itself be a result, or that it represents a need to readdress aspects of a project, is a critical skill that a student must accept. In accepting failure and taking pride in quality, a student stops craving the answer and starts craving pathways to knowledge.

Defense and Presentation - Through research, students refine their ability to analyze and draw conclusions from the data that they gathered, and learn to present it in a concise, well-articulated form to an audience. Much like collaboration, the final defense and presentation of their project teaches them how to represent data, speak publically about their work, write scientifically, and again, how to take pride in the work that they have done. Whether this defense and presentation comes in the form of a peer presentation, a science fair submission, poster presentation, or an abstract or journal article, this defense makes a student reevaluate the lessons that they have learned through the first five pillars, and display to others the person that they have become throughout the process. 
On paper, these six concepts represent the skills that a research student at BCA develops during their high school career. Although the tools used and experiments carried out may be limited and specific to their individual project, the skills they learn by developing and carrying out the project are transferable to every stage of their education and careers that will follow after BCA. The ability to think critically analyze, collaborate and make presentations are all crucial skills in any career, especially in STEM fields. The confidence in these skills that a student is able to craft at BCA not only gives them an advantage in their future endeavors, but puts them on a course to become part of the next generation of leaders in STEM.

\subsection{Student achievements and benefits}

Although BCA's pillars of research show conceptually what students supplementing their education with research gain through participation, there are also a number of academic achievements that research students at BCA have gained because of their work. Some examples include research accolades, publications, and college acceptances.

There is no question that BCA students participating in research have an advantage over other students when it comes to the technology and instrumentation at their disposal. When competing in local science fairs and competitions, BCA students typically receive multiple awards. Even more impressive is how these students perform at the national level. The best example comes from student achievement in the Intel Science Talent Search, which is widely considered to be the most rigorous and prestigious science competition for high school students in the country. Since 2009, BCA has had seven semi-finalists and two finalists in the competition. The work done by these students is exemplary and their project design and results are evidence of the quality of the research projects at BCA.

While science fairs have projects competing against each other in order to determine a winner, publications and presentations at conferences introduce projects to the entire scientific community. Students participating in research involving microscopy at BCA are an excellent example of student publication and poster presentations. Since 2008 when the NSIL opened, 14 students have been published in 12 abstracts to the Microscopy and Microanalysis annual conference, with 4 attending the conference and presenting their posters to the scientific community. In addition, 5 students have been co-authored or acknowledged for their work on 4 peer-reviewed journal articles. Although not every student project culminates in publication, the possibility is present for every student. Those that do leave with a publication or poster presentation have something that they can reference on a college application and resume, and helps them stand out from a field of applicants.

A final way that students' achievement can be measured is by matriculation into quality educational institutions where they can pursue their ambitions in STEM fields. Of the 72 AAST graduating seniors in the class of $2012^{7}$, the following students have matriculated in either Ivy league schools or one of the top 10 ranked engineering schools for 2012 as reported by U.S. News ${ }^{8}$ : Carnegie Mellon University (2); Columbia University (5); Cornell University (5); Harvard University (1); Massachusetts Institute of Technology (1); Princeton University (6); University of California, Berkeley (6); Yale University (2). In total, 28 of the 72 students, nearly 39\% of the AAST graduating class, are attending some of the top colleges in the nation, often pursuing a degree in a STEM related discipline.

\subsection{Future direction}

Moving forward, the administration and faculty of BCA see three important objectives to expanding its capacity for developing the STEM/research leaders and innovators necessary in order to remain successful and demonstrate the success of the programs offered. The first is continued and improved tracking of alumni through college and graduate studies and into their careers. The research program at BCA took its current form beginning in the 2005-2006 school year, and limited data is available on the career paths of those students who have participated in research. With improved data over the next few years, the administration of the school, as well as those in support of reforming STEM education, will be able to better support the idea that student exposure to research and more interactive STEM education leads to a higher incidence of STEM professionals. 
A second objective is to continue to align with national frameworks for STEM education and serve as a model for STEM education in the high school setting. BCA provides an environment where students are challenged to think like a scientist rather than a student, and provides the students with many of the tools needed to be a scientist. The successes of the program, as shown through student benefits, accolades, and career tracking, when aligned to broader initiatives, can allow BCA to continue to fund the research, expand its resources, and serve as a model for reformed STEM education in the U.S.

Finally, the administration, faculty and staff of BCA believe that through the work performed within the walls of the school, they are developing the next generation of STEM leaders as called for by the NSF, NSB, and President of the United States, among others. As shown earlier, a new generation of STEM leaders in the U.S. will be necessary to not only replace the aging generation leading American ingenuity and discovery today, but also to ensure that the U.S. remains a leader in the world community in STEM output for years to come.

\section{ACKNOWLEDGEMENTS}

The authors would like to acknowledge the following people for their contributions, dedication and continued support: Dr. Howard Lerner, Superintendent, Edmund Hayward, Director of Technology, and the administration of the Bergen County Technical School District; the Bergen County Technical School District Board of Education; Russell Davis, Principal, and the administration of the Bergen County Academies; the faculty members: Dr. Robert Pergolizzi, Donna Leonardi and Dr. Deok-Yang Kim; and the Bergen County Board of Chosen Freeholders.

\section{REFERENCES}

[1] Robinson, K., "RSA Lecture - Changing Paradigms," Royal Society for the encouragement of Arts, Manufactures and Commerce, 14 October 2010. <http://www.thersa.org/events/video/archive/sir-ken-robinson> (23 March 2012).

[2] "The Competitiveness and Innovative Capacity of the United States: Chapter 4 - Educating Our Workforce," U.S. Department of Commerce \& The National Economic Council, January 2012.

$<$ http://www.commerce.gov/sites/default/files/documents/2012/january/competes_010511_0.pdf> (23 March 2012).

[3] National Research Council of the National Academies [A Framework for K-12 Science Education: Practices, Crosscutting Concepts and Core Ideas] National Academies Press, Washington, DC, foreward, 8, 10, 41-42 (2012).

[4] "Preparing the Next Generation of STEM Innovators: Identifying and Developing Our Nation's Human Capital," National Science Board Committee on Education and Human Resources, 5 May 2010. $<$ www.nsf.gov/nsb/publications/2010/nsb1033.pdf> (23 March 2012).

[5] Zumeta, W. and Raveling, J. "The Best and Brightest for Science: Is There a Problem Here?" Commission on Professionals in Science and Technology, August 2002. <http://www.cpst.org/BBIssues.pdf> (23 March 2012).

[6] "President Obama Launches 'Educate to Innovate' Campaign for Excellence in Science, Technology, Engineering \& Math (STEM) Education," White House, Office of the Press Secretary, 23 November 2009. $<$ http://www.whitehouse.gov/the-press-office/president-obama-launches-educate-innovate-campaign-excellencescience-technology-en> (23 March 2012)

[7] "Bergen County Academies: Academy for The Advancement of Science \& Technology Class of 2012 College Profile," Bergen County Academies, March 2012. $<$ http://bcts.bergen.org/images/stories/BCTS/pdf/AAST_profile\%202012\%20updated.pdf> (23 March 2012).

[8] “U.S. News 2012 Best Engineering Schools Rankings and Reviews,” U.S. News, 2012. $<$ http://grad-schools.usnews.rankingsandreviews.com/best-graduate-schools/top-engineering-schools/eng-rankings> (23 March 2012) 